\title{
TRANSOESOPHAGEAL AORTIC VELOGRAPHY IN MAN
}

\author{
P.J. Tomlin ${ }^{1}$ and F.A. DuCk ${ }^{2}$
}

THE SEARCH for a non-injurious technique for monitoring myocardial performance that is applicable to anaesthetized patients has been prolonged. The solution of this problem that is in widespread use is the continuous oscilloscopic display of the electrocardiograph. This only gives information that relates to changes in the impulse origin or propagative properties of the heart and as such is not an ideal monitor; in anaesthesia the changes in the mechanical properties of the heart are of more immediate clinical interest. Indeed it is not outside the experience of many anaesthetists to have a patient with a near-normal electrocardiogram on an oscilloscope while the patient has little to no cardiac output, as in post-cardiac-arrest situations. This is not to decry the use of the e.c.g. in anaesthesia. Indeed, when inhalational anaesthetic vapours were in common use, the onset of irregularity of the e.c.g. provided a valuable early warning of the increased irritability of the myocardium produced by these vapours.

The more modern techniques of anaesthesia, with their emphasis on the use of relaxants, sub-normal $\mathrm{P}_{\mathrm{CO}_{2}}$ levels and narcotic supplementation have reduced the dangers due to instability of the myocardial muscle membrane potential, but have substituted the hazard of myocardial depression with reduced ventricular performance, which the e.c.g. display unit cannot show.

An ideal specification for a device that could monitor the state of myocardial performance could be that it should be non-injurious to the patient, require little to no calibration, be subject to minimal electrical distortion within the environment of the operating theatre and, finally, that it should monitor some aspect of the mechanics of the heart and display this information in an easily assimilable form. Hitherto, equipment capable of meeting all these specifications has not been available. However, we have recently had an opportunity of evaluating a technique of monitoring the circulation which incorporated a device that seems to meet these criteria. The preliminary qualitative results were sufficiently interesting to warrant their presentation here. The technique is trans-oesophageal aortic velography; that is, recording of the velocity of aortic blood flow detected by means of an intraoesophageal Doppler probe. This technique has not been used before in man.

From Departments of Anaesthesia and Radiology, Memorial University, St. Johns, Newfoundland.

Current address:

1P.J. Tomlin, M.B., B.S., F.F.A.R.C.S., University Department of Anaesthetics, Queen Elizabeth Hospital, University of Birmingham, England.

2F.A. Duck, M.Sc., Department of Physiology and Biophysics, Mayo Foundation, Rochester, Minnesota, U.S.A. 


\section{Methods}

The equipment used was a Doppler device inside a Ryles tube. This could be passed down the oesophagus of an anaesthetized patient to observe the velocity of blood flowing down the descending aorta at a level just above the diaphragm. The device itself consisted of two D-shaped piezo-ceramic plates of zirconate titanate (PZT5) alongside each other, one of which acted as the transmitter, the other the receiver of ultrasound. The plates were obtained by bisecting in the long axis an elliptical plate measuring 3.5 by $2.0 \mathrm{~mm}$ and mounting them in epoxy resin inside a Ryles tube of $5 \mathrm{~mm} \mathrm{O.D.} \mathrm{so} \mathrm{that} \mathrm{the} \mathrm{plates} \mathrm{were} \mathrm{at} 45^{\circ}$ to the long axis of the tube. Electrical connection to the plates was by co-axial cable threaded down the tube and secured with epoxy resin. Full details of the construction of the probe and its acoustic properties have been described elsewhere (Duck, Hodson \& Tomlin). ${ }^{1}$

The beam of ultrasound was produced by stimulating the transmitter plate continuously at a frequency of $8 \mathrm{MHz}$ with the high frequency oscillator of a Parks 806 Doppler blood velocity meter, to which the receiver plate was also attached. After demodulating the back-reflected ultrasound signal and after passing the signal through a zero crossing ratemeter, the resulting output was the Doppler shift of the ultrasound, produced as the sound waves were reflected by the moving particles (i.e. blood cells) in the blood stream.

The velocity of the blood stream can then be calculated according to the equation. ${ }^{2}$

$$
\begin{aligned}
& \text { Equation (i) } \mathrm{df}=2 f v \operatorname{Cos} \theta / \mathrm{c} \\
& \text { where } \quad \mathrm{df}=\text { Doppler shift } \\
& f=\text { emitting frequency of ultrasound } \\
& c=\text { velocity of sound in tissues } \\
& \theta=\text { the angle between the sonic beam and the direction } \\
& \text { of blood flow } \\
& \mathbf{v}=\text { velocity of blood flow }
\end{aligned}
$$

One critical component of the technique is the angle between the flow stream and the sound beam. By choosing to position the probe inside the oesophagus (that is inside a long tube which is, to all intents and purposes, parallel to the aorta ), a reasonably constant angle between the blood flow and sound beam was maintained.

Previous experimental work in animals had established ${ }^{3,4}$ a marked parallelism at all phases of the cardiac cycle between the output of the Doppler equipment, measuring velocity, and the output of an electromagnetic flowmeter probe placed around the descending aorta approximately $2.5 \mathrm{~cm}$ proximal to the ultrasonic probe located in the oesophagus about $2.5 \mathrm{~cm}$ above the diaphragm. These studies showed that there were two cycles of flow and velocity in the descending aorta, a larger one occurring during systole, and a second smaller cycle occurring in diastole. This second cycle was due to recoil of the upper aorta as blood was discharged to the periphery during diastole. It was also shown that the relative size of the diastolic wave was related to the total peripheral resistance, this being 
TABLE I

Patients Studied with Transoesophageal Probe

\begin{tabular}{|c|c|c|c|}
\hline & Patient & Operation & Quality of record \\
\hline $\begin{array}{l}1 . \\
2 . \\
3 . \\
4 . \\
5 . \\
6 . \\
7 . \\
8 . \\
9 . \\
10 . \\
11 . \\
12 . \\
13 . \\
14 . \\
15 .\end{array}$ & $\begin{array}{l}\text { Male H.S. } \\
\text { Male W.A. } \\
\text { Female M.T. } \\
\text { Male C.OL } \\
\text { Male S.M. } \\
\text { Male A.W. } \\
\text { Female M.N. } \\
\text { Female M.B. } \\
\text { Female C.H. } \\
\text { Male J.N. } \\
\text { Female S.L. } \\
\text { Male T.B. } \\
\text { Male L.E. } \\
\text { Male C.C. } \\
\text { Male J.W. }\end{array}$ & $\begin{array}{l}\text { Cystoscopy } \\
\text { Cystoscopy } \\
\text { Tubal Ligation } \\
\text { Cystoscopy } \\
\text { Cholecystectomy } \\
\text { Total Hip Replacement } \\
\text { Pinning Femoral Neck } \\
\text { Tubal Ligation } \\
\text { Tubal Ligation } \\
\text { Tarsal fusion } \\
\text { Hysterectomy } \\
\text { Laparotomy } \\
\text { Ureteric Calculi } \\
\text { Prostatectomy } \\
\text { Fem-Pop. Bypass graft }\end{array}$ & $\begin{array}{l}\text { Operation too short } \\
\text { Operation too short } \\
\text { Good } \\
\text { Good } \\
\text { Good Figure } 3 \\
\text { Poor Noisy signal } \\
\text { Poor Noisy signal } \\
\text { Good Figure } 4 \\
\text { Good } \\
\text { Poor Noisy signal } \\
\text { Good } \\
\text { Good } \\
\text { Good } \\
\text { Good } \\
\text { Good-Figure } 1,2 .\end{array}$ \\
\hline
\end{tabular}

the prime reason why the upper aorta had distended so much. Furthermore these studies showed that the ratio between peak acceleration and the instantaneous velocity at the time of peak acceleration, or $\max \mathrm{dV} / \mathrm{dt} \div \mathrm{I} . \mathrm{V}$, was related to myocardial contractility as measured invasively by $\mathrm{dP} / \mathrm{dt}$ max divided by the instantaneous developed pressure of the left ventricle.

For the investigation in human subjects no means of assessing the exact state of myocardial contractility was available nor was there an exact in vivo calibration of ultrasonic signals. The results are therefore presented as qualitative changes in the signals as recorded.

The investigation consisted of passing the probe down the oesophagus of 15 anaesthetized patients requiring a variety of operations (see Table 1 ). The demodulated Doppler-shifted output from the probe was recorded on a high quality audio tape recorder, and simultaneously displayed on a standard e.c.g. oscilloscope. A second channel on the tape recorder was used for a verbal record of events as they occurred during anaesthesia and operation. The tape was subsequently replayed onto a conventional pen recorder. The spectrum of the tape recorded signal was also analysed to determine the intensity-frequency spread of ultrasound and so to determine the instantaneous range of velocities and proportion of flow occurring at any velocity. If there was a wide spread of velocities and, particularly, if there was wide range of intensities at these different velocities, then it was deduced that turbulent flow was being observed.

\section{ResUlts}

The first two patients did not produce signals suitable for analysis. Both patients were anaesthetized for cystoscopic examination and the anaesthesia was completed within 15 minutes. Subsequent analysis of the results from all the other patients confirmed that it took the human oesophagus of the lightly anaesthetized patient approximately 15 minutes to accommodate to the presence of the intra-oesophageal probe regardless of the anaesthetic used. Re-examination of our results from the 

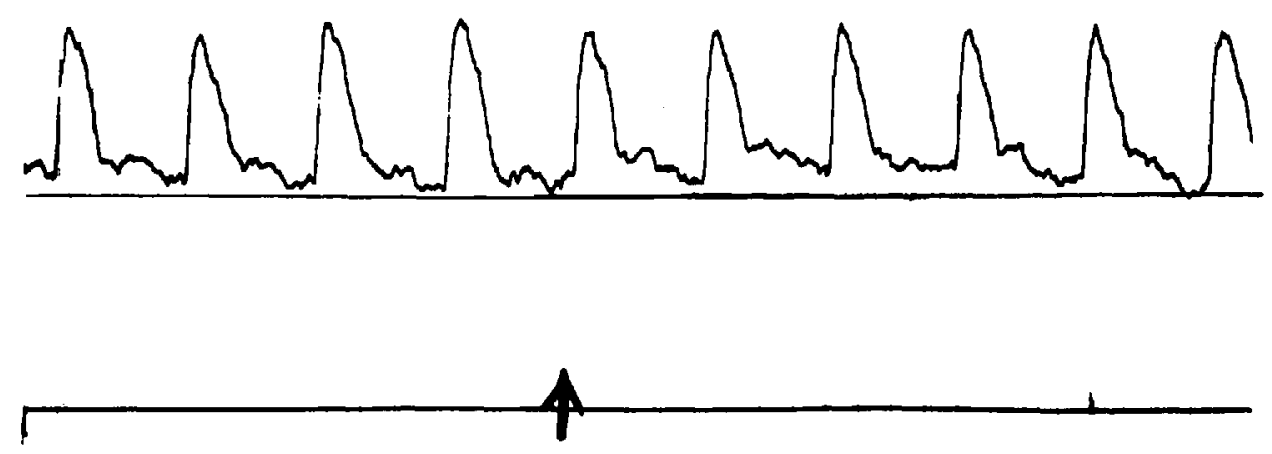

Figure 1. The nature of the velocity signals observed in the descending aorta and the effect of a step change in total peripheral resistance in man on the diastolic velocity wave.

At the time indicated by the arrow the saphenous vein by-pass graft was transiently occluded. This produced an immediate enlargement of the diastolic velocity wave area.

Upper line is the 1 second time marker.

dog experiments showed that these animals took up to four minutes to accommodate to the presence of a probe in the oesophagus. Presumably the difference in sensitivity of the oesophagus to the foreign body reflects a species difference. Tests of thermal disequilibrium by placing the probe in flows of fluctuating temperatures in vitro, or of inadequate liquid coupling by filling the oesophagus with water, could not reproduce or modify these initial fluctuating discordant signals. Thereafter, over the next minute or so, regular good quality signals were obtained. An example of this is seen in Figure 1. In three other patients noisy signals were obtained throughout, but this was traced to an excessive A-C voltage on the grounding channel of that particular operating room, which presumably was causing interference with the circuit amplifiers.

Figure 2 shows the changes in signal as the probe is withdrawn up the oesophagus. At or near the level of the arch of the aorta a characteristic polyphasic cycle is seen. Spectrographic analysis revealed considerable turbulence at this level. As the probe is moved more proximal still another regular pattern can be seen. This is a triple-humped pattern with very sharply defined peaks. This same pattern can be obtained by applying the probe externally over a small artery. The significance of this triple-humped pattern is obscure.

Figure 1 is of further interest because it demonstrates the effect of a small change in peripheral resistance on the diastolic wave. This patient presented for a femoral popliteal bypass graft for peripheral arterial disease. At the time of recording the graft had been completed, but at the arrow point the surgeon occluded the graft for a few seconds. An immediate small increase in the relative size of the diastolic hump is observed, although the occlusion produced no change in blood pressure as measured with a sphygnomanometer cuff. This finding accords with the changes in peripheral resistance on the diastolic wave in our animal results. ${ }^{3}$ Although no figures are available for the peripheral resistance in this patient, in normal resting 


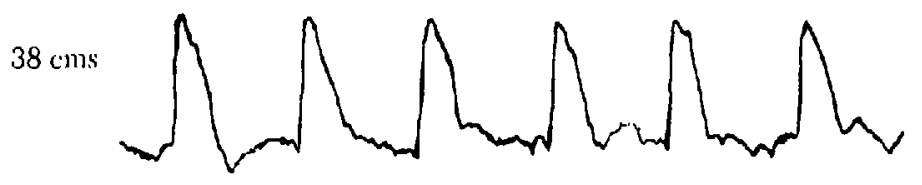

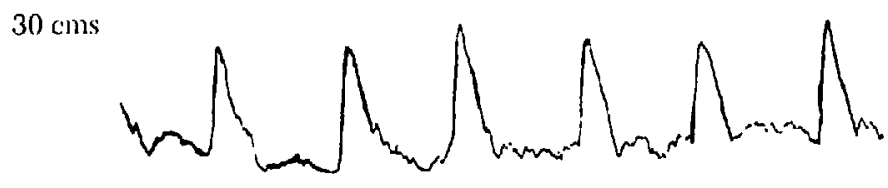
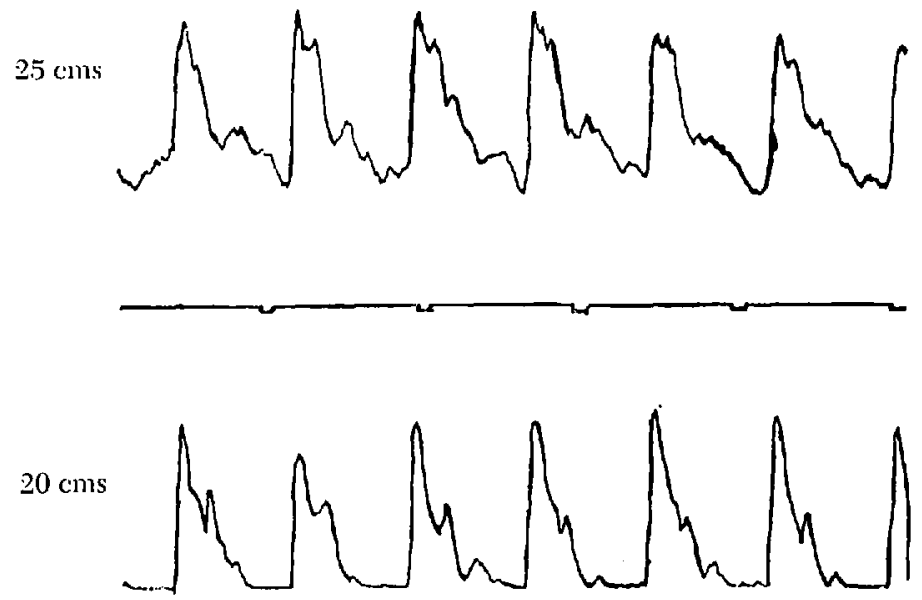

Figure 2. The changes in blood velocity profile along the descending aorta in man. All distances indicated are those measured from the incisor teeth. Note that the diastolic velocity wave is much smaller near the arch of the aorta. At the arch a polyphasic turbulent wave appears. More proximal to this triphasic waves are observed similar to those obtainable from small arteries in man.

patients the femoral artery and its associated branches can be calculated to contribute less than 10 per cent to the total peripheral resistance (Wade \& Bishop) ${ }^{5}$, yet occluding the femoral artery graft in this patient produced a detectable change in the velocity record.

A record of aortic blood velocity during a difficult cholecystectomy is shown in 


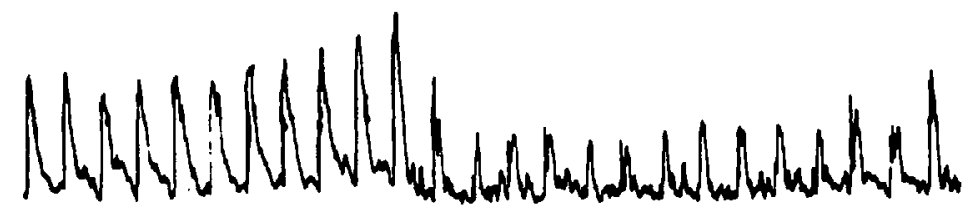

A. Traction around the Coeliac Axis

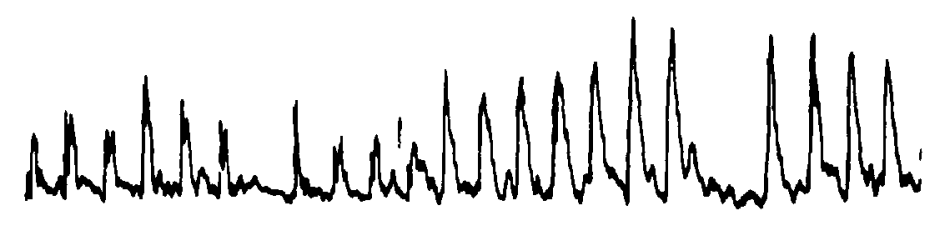

B. Continuation of $A$. Note the dropped beats

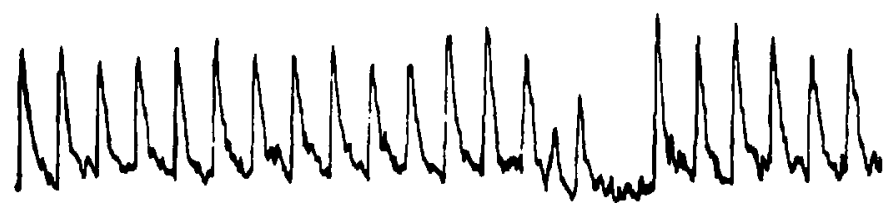

C. 40 secs. later on ectopic beat preceded by 2 irregular beats with reduced Ventricular Ejection

Figure 3. The effect of sudden surgical stimulus on the velocity profile. The record was obtained from a patient undergoing cholecystectomy. Lines A and B are continuous and overlap slightly. Line $\mathrm{C}$ was recorded 40 seconds later than the end of Line $\mathrm{B}$.

Figure 3. At the time of the record the surgeon was having difficulties in access to the common bile duct and there was considerable traction around the coeliac axis. The effect of this was an abrupt fall in peak aortic velocity and a reduction in peak acceleration (steepness of the rise in signal), which may be interpreted as reflex vagal depression of the myocardium with a reduced force of ventricular ejection. This was associated with a small change in heart rate from 100 to 92 beats per minute and was followed by episodes of dropped beats, which were not immediately followed by beats with a compensatory extra large flow.

Figure 4 is a record of aortic blood velocity while the patient was being anaesthetized for an open tubal ligation. The anaesthetic sequence chosen included the use of intermittent doses of suxamethonium. Due to a communications failure she had not been given any atropine premedication. After the third increment of 


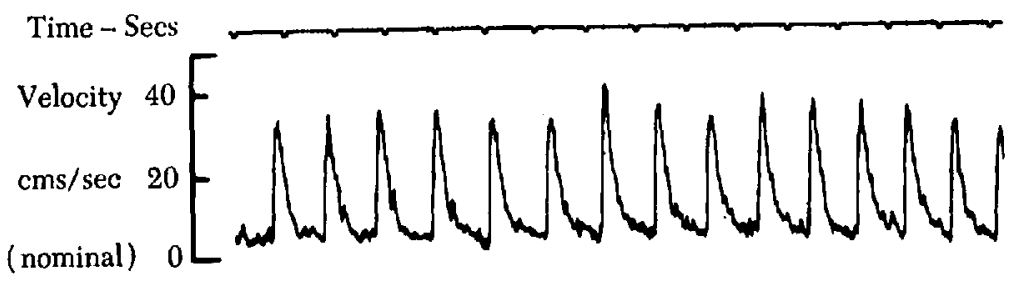

A. Control

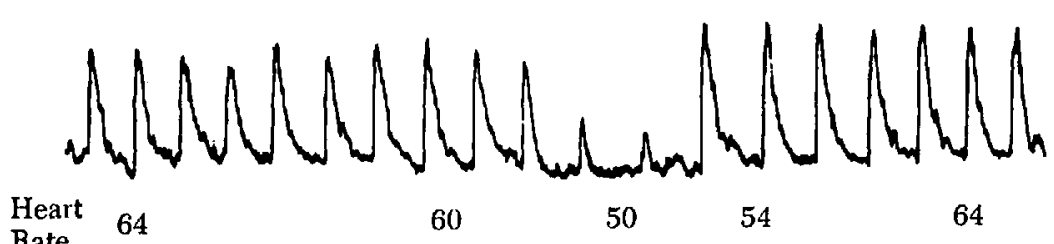

B. After the third Increment of $25 \mathrm{mg}$.

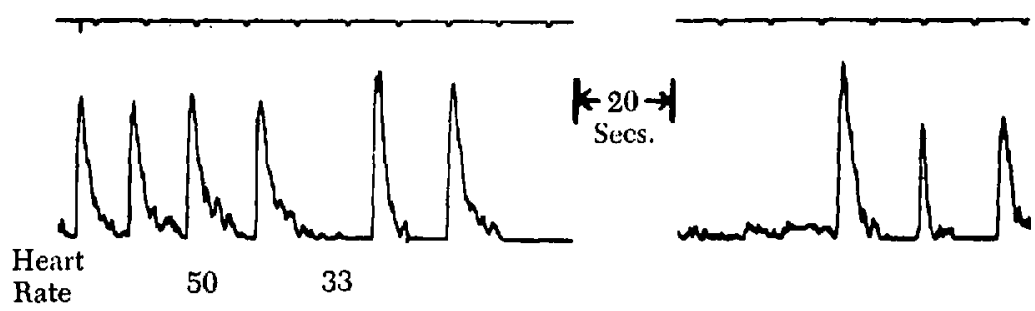

C. After the fourth increment of $25 \mathrm{mg}$.

Figure 4. Intermittent suxamethonium on aortic blood velocity. After the third increment of suxamethonium there was bradycardia and reduced myocardial contractility (Max $\mathrm{dV} / \mathrm{dt} \div$ instantaneous Velocity) and peak velocity. The fourth increment produced asystole lasting 23 seconds.

suxamethonium there was a very transient bradycardia which recovered within 20 seconds, but included two beats of very reduced ventricular ejection characterized by a more sluggish rise in the velocity signal (reduced acceleration) and markedly reduced peak velocity; that is, $\max \mathrm{dV} / \mathrm{dt} \div \mathrm{V}$. max or myocardial contractility, ${ }^{4}$ was reduced. After the fourth increment of suxamethonium there was total ventricular standstill. It was the oscilloscopic display of the velocity signal that drew attention to this, and it was confirmed when palpation revealed NO apex beat and absence of radial pulse associated with some pallor. The anaesthetist elected to wait for vagal escape to occur rather than instituting other resuscitative procedures and normal rhythm eventually returned after 23 seconds of circulatory arrest. Within the next half-minute normal circulatory parameters were recorded and the patient was then treated with $0.6 \mathrm{mg}$ of atropine. The effect of this drug was to abolish this type of response to further increments of suxamethonium. Half an hour after the anaesthetic was discontinued the patient was 
conscious, fully orientated and talking normally and was discharged home next day. This response has been well described ${ }^{6}$ although such a prolonged asystole following suxamethonium appears not to have been reported previously. It is of interest that the episode of bradycardia and marked alteration in velocity profile after the third increment had given a clear warning of this response. This combination, it is suggested, offers a more clear-cut warning of severe vagal overactivity than does the display of simple bradycardia that a conventional e.c.g. might show. It was also of interest that the circulatory haemodynamics in terms of flow and velocity returned so quickly to normal after this somewhat prolonged episode of ventricular stand-still.

\section{Discussion}

The purpose of this investigation was to determine if good-quality signals of aortic blood velocity could be obtained from patients undergoing elective surgery, and to see if they were capable of a qualitative interpretation. This proved to be the case. Signals which could be interpreted were obtained with little difficulty, despite the absence of a clear quantifiable calibration technique. Interpretation was a matter of pattern recognition. Pattern recognition is a technique used in other fields, e.c.g. interpretation being an example. An internal calibration signal was incorporated into the system, but since the angle between the ultrasonic beam and aortic blood flow was not measured this calibration was nominal only, like the $50 \mathrm{mv}$ calibration signal used in electrocardiography. In neither case does the signal have a precise meaning in indicating an exact quantitative biophysical change. The problem of calibration applies to all non-invasive Doppler techniques because of the angular dependence of the extent of Doppler shift between the ultrasound beam and the direction of flow. Fahrbach ${ }^{\tau}$ has proposed an ingenious solution to this, by using two beams set at right angles to each other, so that one beam looks upstream and the other downstream. The root of the sum of the squares of the outputs is the absolute Doppler shift and is independent of the angle between the sound beams and the direction of blood flow. This is so because the sum of $\operatorname{Cos}^{2} \theta$ and $\operatorname{Cos}^{2}(90-\theta)$ is unity, and the angle factor of equation 1 therefore cancels out. Preliminary testing of such a double probe has shown that over a range of $\pm 20^{\circ}$ from the $45^{\circ}$ angle between the sound beam and direction of flow, ${ }^{8}$ the angle factor is insignificant. However, a suitable atraumatic double probe that could be used in man was not available for this study.

The choice of the lower thoracic aorta as the site to observe the velocity of flow was a deliberate one. Apart from having a reliable angular alignment by the probe itself, we were interested in seeing if the diastolic hump effect of the elastic and distensible upper aorta responsive to changes in peripheral resistance which we had observed in the dog applied also in man. The further the probe was down the oesophagus the greater was the volume of aorta available for diastolic recoil and, therefore, the greater the size of the diastolic velocity wave. Should the diastolic velocity wave area relative to the total velocity wave area prove to be quantitatively related to the peripheral resistance in man, as it is in the $\mathrm{dog}_{,}{ }^{3}$ this would be an added advantage. In the event, the diastolic velocity wave was not as clearcut in man as it was in the dog. Empirically the optimum position was found to be about $2.5 \mathrm{~cm}$ above the diaphragm. If the probe tip entered the stomach there was 
an immediate loss of signal. This was because the gastric air bubble failed to conduct the beam of ultrasound. Air acts as an insulator to sound waves when these are in the $\mathrm{MHz}$ range. It was found that unless the probe was withdrawn to at least 2 to $3 \mathrm{~cm}$ above the point where signals were lost, then continuous velocity signals were not obtainable throughout the respiratory cycle. Furthermore, the last part of the oesophagus is not parallel to the aorta, but is moving to the left to pass through the crura of the diaphragm.

Light ${ }^{\circ}$ has proposed that the arch of the aorta should be viewed by the ultrasound beam, directed through the suprasternal notch. However, this approach raises several problems. At this level we have observed considerable turbulence as indicated by the spectrographic analysis of the Doppler shifted ultrasonic signals, where a considerable range of velocities can be seen throughout the whole of the cardiac cycle. However, a more basic criticism can be made. At this level the vessel is curving away from the probe, and the depth of penetration of the beam of ultrasound is unknown. It is theoretically possible for the same red cell (or group of red cells) early in systole to give one level of Doppler shifted frequency of the reflection of the ultrasound. Later in systole because its direction of movement has changed as it passed around the curvature of the aorta, this same red cell could give another and perhaps lower level of Doppler shift, without change of velocity. This could coincide with the entry into the viewing zone of the arch of the aorta of another red cell, the velocity of which is reduced due to the waning of systole and, therefore, exhibiting a reduced Doppler shift of the reflection of ultrasound. This situation, given the population of red cells, the cyclical nature of velocity during the cardiac cycle, and the curvature of the arch of the aorta, must apply at some point during systole. Therefore, the intensity of the signal at any Doppler shifted frequency that is below maximum is unquantifiable. If the electrical apparatus gives the instantaneous mean velocity from the mean intensity of signal this could be erroneous due to the distortion of the mean produced by this type of artifact.

To circumvent this, instantaneous spectrographic analysis of the Doppler shifted signals has been suggested. ${ }^{10}$ Then only the instantaneous maximum velocity should be used. This had led to a very considerable complexity of the apparatus used in order to perform this analysis and to the impossibility of relating velocity to flow, as the flow profile cannot be known. However, the use of the supra-sternal notch to view the arch of the aorta does have one advantage. Because of the anatomical configuration the ultrasonic beam, at some part of the aortic arch, is pointing directly along the direction of the blood flow. Under these circumstances the magnitude of the Doppler shift is maximal, and even an error of $10^{\circ}$ in alignment between the beam and the direction of flow will cause an error of only 2 per cent in the magnitude of the Doppler shift, because from 0 to $10^{\circ}$ the values of $\operatorname{Cos} \theta$ change only by this amount. Notwithstanding this, the problems of maintaining constant angular alignment and fixation of the probe to the suprasternal notch, as well as the complexity and consequent high cost of the apparatus to avoid errors due to changes in direction of movement seem to render it unsuitable as an aid for the continuous monitoring of the circulation during anaesthesia.

An alternative non-invasive approach for monitoring myocardial performance that has been suggested is impedance cardiography. ${ }^{11-13}$ In this technique a 
high frequency alternating current is continuously passed up and down the chest and the changes in thoracic impedance are measured as they occur during the cardiac cycle. Kubicek et al. ${ }^{11}$ have found a relationship between the maximum rate of change of impedance $\mathrm{dZ} / \mathrm{dt} \max$ and peak aortic flow. Hill et al..$^{13}$ have used this $\mathrm{dZ} / \mathrm{dt}$ max as a means of calculating stroke volume and have thereby derived cardiac output, although they have not indicated how they were able to calibrate the apparatus. The published tracings of impedance change and its differential do not resemble the flow signals that are obtainable from an electromagnetic flow meter probe on the ascending aorta. Presumably these changes in impedance are due to changes in the blood gas interface as the pulmonary capillaries become distended with blood during cardiac cycle. This would alter the lines by which an electrical current can flow and within the chest there is little else that can change to electrical impedance so markedly. Support for this hypothesis may be found in the work of Kira, et al. ${ }^{14}$ If this hypothesis is correct, changes in impedance cannot directly reflect changes in myocardial contractility, since much of the energy imparted to the flow will have been dissipated in overcoming the pulmonary vascular resistance. Seigel et al. ${ }^{12}$ have managed to use the changes in impedance as time markers to derive the isometric time tension index, which is an indirect correlate of myocardial contractility. However, all these approaches have required additional channels of information, some requiring an invasive approach; and this increases the complexity and so the ability to obtain easily the data the clinician may be seeking.

The preliminary findings reported here would suggest that continuous transoesophageal aortic velography using the Doppler shift of ultrasound could play a useful role in helping the anaesthetist evaluate the state of the circulation of his patients, particularly if a little time is allowed for the oesophagus to accommodate to the presence of the probe. An initial step would be a matter of pattern recognition, though it should be possible to develop suitable black boxes capable of determining $\mathrm{dV} / \mathrm{dt} \max \div \mathrm{V}$. $\max$ and the ratio of diastolic velocity area to total area, to give quantitative information about the state of myocardial contractility and total systemic vascular resistance.

\section{SUMMARY}

An ultrasonic probe placed in the oesophagus of anaesthetized patients was used to observe the velocity of the blood flow down the descending aorta. The operating principle of the technique was the Doppler shift of the reflection of a continuously emitted $\mathrm{MHz}$ beam of ultrasound. The human oesophagus took up to 15 minutes to accommodate to the presence of the probe in the oesophagus. Changes in the diastolic portion of the flow pattern were seen with small changes in peripheral resistance (produced by transiently obstructing a femoral popliteal by-pass graft) (Figure 1). Surgical stimuli also produced marked changes in the flow pattern (Figure 3) before arrhythmias occurred. Following a prolonged period of cardiac arrest the flow pattern was observed to return to normal very quickly (Figure 4).

It is suggested that the ultrasonic trans-oesophageal probe could play a useful role in patient monitoring in anaesthesia. 


\section{RÉSUMÉ}

Une sonde ultrasonique placée dans l'œsophage de patients anesthésiés servit à observer la vélocité du sang au niveau de l'aorte descendante. Le principe à la base de cette technique est la déviation Doppler de la réflexion d'un faisceau continu d'ultrasons, d'une fréquence de $8 \mathrm{MHz}$. L'œsophage humain prend jusqu'à 15 minutes pour s'habituer à la présence de cette sonde. Des altérations dans la portion diastolique du tracé de débit apparaissent à la suite de variations minimes de la résistance périphérique (produit par le clampage transitoire d'un greffon fémoro-poplité) (fig. 1). Les stimulations chirurgicales provoquent aussi des changements importants sur le tracé (fig. 3) précédant l'apparition d'arythmies. A la suite d'une période prolongée d'arrêt cardiaque, le tracé de débit a démontré un retour rapide vers la normale (fig. 4).

La sonde ultrasonique transoesophagienne pourrait jouer un rôle utile dans la surveillance des patients sous anesthésie.

\section{ACKNOWLEDGMENTS}

The authors would like to express their thanks to Dr. J.C. Hodson, Department of Radiology, Memorial University, St. Johns, Newfoundland for making this study possible, and to the Canadian Heart Foundation for financial support.

\section{REFERENCES}

1. Duck, F.A., Honson, C.J., \& Tomun, P.J. An oesophageal Doppler probe for aortic flow velocity monitoring. Ultrasound in Med. and Biol. I: 233 (1974).

2. Side, C.D. \& Gosling, R.G. Non-surgical assessment of cardiac function. Nature 232: 335 (1971).

3. Tomlin, P.J. \& Duck, F.A. Total peripheral resistance and diastolic blood flow C.A.S.J. 21: $482(1974)$.

4. Tomlin, P.J. \& Duck, F.A., McNulty, M. \& Green, C. A comparison of methods of evaluating myocardial contractility. Submitted to C.A.S.J. (1975).

5. WADE, O.L. \& Bishor, J.M. Cardiac output and regional blood flow. Oxford, Blackwell. P. 86 ( 1962 ).

6. Luppaian, K.G. \& Churchill-Davidson. The effects of suxamethonium on cardiac rhythm. Brit. Med. J. 1: 1774 (1960).

7. FaHRBACH, K. Ein Beitrag zur bludgeschwindigkeitsmessung unter Anwendung des Doppler effekts. Elektro medizin 15: 26 (1970).

8. Duck, F.A. \& Honson, C.J. A practical way of eliminating the angular dependence of Doppler flow measurement. Proc. 2nd World Congress on Ultrasonics in Medicine.

9. Light, L.H. Transcutaneous observations of blood velocity in the ascending aorta in man. J. Physiol. 204: I.P. (1969).

10. LIGHT, L.H. A recording spectrograph for analysing Doppler blood velocity signals in real time. J. Physiol, 207: 42 (1970).

11. KubiceK, W.G., Ketrle, F.O., Ramos, M.U,, Patterson, R.P., Witsoe, D.A., Labhee, J.W., Rennoles, W., Layman, T.C., Schoenig, H., \& Garamela, J.T. The Minnesota Impedance Cardiograph, theory and applications. Biomedical Engineering 9: 410 (1974)

12. Seiger, J.H., Gebian, M., Lapkau, C., Levine, M., Cole, A., \& Nahmead, M. Clinical and experimental use of thoracic impedance plethysmography in quantifying myocardial contractility. Surgery 67: 907 (1970).

13. HiLl, D.W. \& Lowe, H.J. The use of the electrical impedance technique for the monitoring of cardiac output and blood flow during anaesthesia. Med. and Biological Engineering 11: $534(1973)$.

14. Kira, S., Hukushima, Y., Kitamura, S., Naka, O.K., Kawakanick, K., Witnabe, A., \& AsHrmA, M. Variations in transthoracic electrical impedance in relation with haemodynamic changes in the pulmonary circulation. Jap. Heart J. $11: 149$ (1970). 